\title{
A Preliminary Assessment and Control Strategy of Size Segregated Pollutants in Urban and Peri-urban Areas of Metropolitan Faisalabad, Pakistan
}

\author{
Khalid Mehmood ${ }^{1,2^{*}}$, Hamaad Raza Ahmad ${ }^{3}$, Abbas Ali Abid ${ }^{2}$ and Ping Guo ${ }^{1,2}$ \\ ${ }^{1}$ Research Center for Air Pollution and Health, College of Environmental and Resource Sciences, Zhejiang \\ University, Hangzhou, Zhejiang 310058, P.R. China. \\ ${ }^{2}$ Key Laboratory of Environmental Remediation and Ecological Health, Ministry of Education, College of \\ Environmental and Resource Sciences, Zhejiang University, Hangzhou, Zhejiang 310058, P.R. China. \\ ${ }^{3}$ Institute of Soil and Environmental Sciences, University of Agriculture, Faisalabad, Pakistan, 38040. \\ *Corresponding Author Email: khalid_mehmood@zju.edu.cn; sipra.khalid@yahoo.com \\ Received 19 January 2018, Revised 08 November 2018, Accepted 30 December 2018
}

\begin{abstract}
In recent years, Pakistan has experienced severe and persistent air pollution associated with urbanization and industrialization and it has substantial affects on ecosystem and air quality. In urban and peri-urban areas, maximum TSP concentrations were observed at Satiana Road (987 $\left.\mu \mathrm{m}^{-3}\right)$ and Chak $215 \mathrm{RB}\left(1123 \mu \mathrm{g} \mathrm{m}^{-3}\right)$. Similarly, maximum $\mathrm{PM}_{10}$ concentrations were recorded at Gutte Wala $\left(782 \mu \mathrm{g} \mathrm{m}^{-3}\right)$ and Chak $215 \mathrm{RB}\left(893 \mu \mathrm{g} \mathrm{m}^{-3}\right)$, while maximum $\mathrm{PM}_{2.5}$ concentrations were observed at Madina Food Mill $\left(621 \mathrm{\mu g} \mathrm{m}^{-3}\right)$ and Chak $215 \mathrm{RB}\left(654 \mu \mathrm{g} \mathrm{m}^{-3}\right)$. The statistical results suggested that there were significant difference between urban and peri-urban areas. Majority of size segregated pollutants including TSP, $\mathrm{PM}_{10}$ and $\mathrm{PM}_{2.5}$ were found with higher values than the United States Environmental Protection Agency (US-EPA), World Health Organization (WHO) and National Environmental Quality Standards for Pakistan (NEQS-Pak) limits for both urban and peri-urban areas. However, only $4 \%, 8 \%$ and $4 \%$ for TSP, $\mathrm{PM}_{10}$ and $\mathrm{PM}_{2.5}$, respectively in urban and in peri-urban samples for TSP $(40 \%) \mathrm{PM}_{10}(60 \%)$ and $\mathrm{PM}_{2.5}$ $(44 \%)$ were found under prescribed guidelines. Furthermore, we have also compared metropolitan size segregated pollutant $\left(\mathrm{PM}_{10}\right)$ with other Pakistan and Asian metropolitan's cities and purposed a control strategy to improve air quality in Faisalabad.
\end{abstract}

Keywords: Size segregated pollutants; $\mathrm{PM}_{10} ; \mathrm{PM}_{2.5}$; Vehicular emissions; Urban; Peri-urban

\section{Introduction}

Atmospheric degradation has become a severe threat to human health and welfare in developing countries like Pakistan, where urbanization, motorization, and industrialization coupled with concomitant growth of energy use are growing rapidly. This threat is severe especially where technologies and strategies for controlling emissions are limited due to lax legislative standards and enforcement of regulations [1-5].

Size segregated pollutants levels are escalating swiftly in urban and peri-urban areas of numerous metropolitan cities especially in developing world [6]. Worldwide, around 3.7 million deaths were reported particularly due to ambient air pollution during 2012 [7], $88 \%$ of these were in low and middle-income countries and this hefty burden of disease was related to size segregated pollutants. Developing countries like Pakistan, there is no exclusion and all metropolitan cities are under severe threats. Approximately, all major cities of Pakistan (Karachi, Lahore and Faisalabad) are facing the menace of air pollution due to expansion of urban land and escalation of traffic emissions [1]. The menace of size segregated pollutants becomes worst at some sites 
where signalized traffic junctions with high pollutants loads, which are further defined as "hot spot" [7]. Globally, Shanghai, Mumbai, Kolkata, Beijing are under great influence of air pollution [8]. It has been well documented that the average $\mathrm{PM}_{10}$ concentration was elevated by more than $5 \%$ in 720 cities annually across the world [8].

Pakistan Environment Protection Agency (Pak-EPA) and Japan International Cooperation Agency (JICA) jointly estimated that the concentration of particulate matter (PM) in large cities of Pakistan are 4.4 to 7.5 times greater than WHO Guidelines [9]. In another finding by PakEPA/JICA analyzed the quality of ambient air in Gujranwala and Faisalabad [9]. In Gujranwala, TSP concentration ( $24 \mathrm{~h}$ avg.) increased up to 5190 $\mu \mathrm{g} \mathrm{m}^{-3}$, which is 30 times greater than WHO guidelines. The environmental assessment report established that PM severe as an environmental and health issue in Pakistan and responsible for 22,000 premature deaths among adults and 700 deaths among children $[10,11]$. Residents closer to main roads, industrial units and in dense settlements are more susceptible to health problems $[12,13,38]$. Rapid increase in population and industries have enhanced pollution to manifold for the residents of big dense population city like Faisalabad. Despite of the fact, it is a third largest city in Pakistan on population basis, but there is no scientific data available regarding air quality status. Considerable researches on rapid increasing levels of size segregated pollutants in urban and industrial areas of developing countries have been well explained, but the peri-urban have scarcely been explored.

The objective of this study was to evaluate the size segregated pollutants in peri-urban and rural locations of Faisalabad, and also to evaluate the preliminary status of urban size segregated pollutants, while considering the US-EPA, WHO, NEQS-Pak guidelines and propose a control strategy. This study could be used as a preliminary assessment in urban and peri-urban to instigate other studies related to source contribution, identification and risk involved to human health. It is also expected that the present work will be useful for controlling and instituting future abatement techniques regarding emission regulations.

\section{Material and Methods Site selection for urban and peri-urban areas}

Faisalabad is located at $73-74^{\circ}$ E, 30$31.15^{\circ} \mathrm{N}$ in geographical map of Pakistan and is the major industrial zone of Pakistan. Therefore, its air quality is an eminent apprehension. The sampling sites for urban areas were selected based on the existing anthropogenic activities such as food processing units, marble factories, flour mills, engineering complexes, chemical and soap factories engineering complexes, busy intersection and commercial centers. It is noted that these areas are the main source of size segregated pollutants. We assumed that potential stationary and mobile sources described by [13] in metropolitan Faisalabad. The sampling sites for peri-urban areas were based on the outskirts areas near clusters of brick kilns, unpaved roads, and heavy traffic load with poorly maintained vehicles. Further, this study was carried out based on the hypothesis that size segregated pollutants changes spatially and temporally largely in terms of concentration, chemical composition and sizes attributes to different types of local sources in Faisalabad areas. In this one month study we were assumed that size segregated pollutants have higher mass concentration on the basis of large anthropogenic activities and favorable meteorological condition (for the deposition of particles with high residence time, relative humidity and low temperature) to elevate mass concentration [14-16].

\section{Monitoring procedures}

Ambient PMs of varying size fraction include TSP, $\mathrm{PM}_{10}$, and $\mathrm{PM}_{2.5}$ were examined with Micro Dust Pro Real Time Particulate Monitor (model HB3275-07, Casella CEL, UK) for 6 hours at each sampling point at height of 2.5 meters above the ground to monitor air quality status in both urban and peri-urban areas during December 02 to 30 December, 2013. Total fifty samples (TSP, $\mathrm{PM}_{10}$ and $\mathrm{PM}_{2.5}$ ) were collected from both urban and peri-urban areas. Micro Dust Pro Real Time Particulate Monitor instrument uses a modulated beam of infra-red light projected to estimate the size segregated pollutants. It includes infra-red emitter, sample volume, infra-red detector and light stop. The detection range of instrument is 0.001 to $2500 \mu \mathrm{m}^{-3}$ with a resolution 
$0.001 \mu \mathrm{g} \mathrm{m}^{-3}$. This apparatus analyzes PM concentration using a near forward angle $\left(12-20^{\circ}\right)$ infrared light $(880 \mathrm{~nm})$ scattering method. A polyurethane foam (PUF) filter adapter (flow rate of $3.5 \mathrm{~L} \mathrm{~min} \mathrm{~m}^{-1}$ ) was applied for size-selective monitoring of airborne size segregated pollutants. The PUF filter encumbered into the adapter that determines the size of PMs being quantify. Filters were available for $\mathrm{PM}_{10}$ and $\mathrm{PM}_{2.5}$ size fractions.

\section{Calibration / standardization}

Micro Dust Pro Real Time Particulate Monitor is individually factory calibrated through gravimetric technique. It can be revert to factory calibration setting using non-degradable calibration insert at any time during its life. We have performed an individual gravimetric (filtered) calibration through possible simultaneous assortment of a gravimetric (filtered) sample of the size segregated PM mass concentration sample. Like this, we have collected two averages (one is from the filter of every size segregated pollutants and second by the mean function within the instrument) sample readings over the exposure duration. In this way, we have derived the possible difference between these two readings and corrected accordingly. In order to ensure high quality and control procedures were followed.

\section{Sampling frequency and statistical analysis}

Monitoring of size segregated pollutants (TSP, $\mathrm{PM}_{10}$ and $\mathrm{PM}_{2.5}$ ) were spread from December 2 to 30, 2013. On sample days, two 6 hours samples were gathered from around 7:30 am to $1: 30 \mathrm{pm}$ and again started from $1: 30 \mathrm{pm}$ to $7: 30$ $\mathrm{pm}$. Please note that samplings were not performed during dust storms and rainy days. Box whisker plot were using IBM SPSS statistics version 23 to assess the difference in urban and peri-urban areas.

\section{Results and Discussion Size segregated pollutants concentration in urban areas}

Maximum TSP concentrations were observed at Satiana road $\left(987 \mu \mathrm{g} \mathrm{m}^{-3}\right)$ followed by Gutt wala (972 $\mu \mathrm{g} \mathrm{m}^{-3}$ ), Railway station (954 $\mu \mathrm{g} \mathrm{\textrm {m } ^ { - 3 }}$ ) (Table 1). Minimum TSP concentration was observed at Al-Noor Home Colony area (154 $\mu \mathrm{g} \mathrm{m}^{-3}$ ) (Table 1). Similarly, maximum $\mathrm{PM}_{10}$ concentrations were recorded at Gutte Wala $(782 \mu$ $\mathrm{gm}^{-3}$ ) followed by Madina Food Mill $\left(754 \mu \mathrm{g} \mathrm{m}^{-3}\right)$, Tariqbad area $\left(735 \mu \mathrm{g} \mathrm{m}^{-3}\right)$. Minimum $\mathrm{PM}_{10}$ concentrations were observed at Alnoor Home Colony area $\left(110 \mu \mathrm{g} \mathrm{m}^{-3}\right)$. Meanwhile, the maximum $\mathrm{PM}_{2.5}$ concentrations were monitored at Madina Food Mill $\left(621 \mu^{-3} \mathrm{~m}^{-3}\right)$, Satina road (458 $\left.\mu \mathrm{g} \mathrm{m}^{-3}\right)$ and Makonwala road $\left(361 \mu \mathrm{g} \mathrm{m}^{-3}\right)$. Size segregated pollutants in urban areas were found highly significant and all of the monitoring points were significantly different from each other. In general, the 6 hours average size segregated pollutant concentrations were higher in urban areas due to high traffic load. Box and whisker plot suggested (TSP, $\mathrm{PM}_{10}$, and $\mathrm{PM}_{2.5}$ ) distributions in urban areas (Fig. 1). The 6 hours TSP concentration in urban areas were varied from 154 to $987 \mu^{-3}$ with average of $662 \mu \mathrm{g} \mathrm{m} \mathrm{m}^{-3}$. Our findings showed that 6 hours $\mathrm{PM}_{10}$ concentrations were assorted from 110 to $782 \mu \mathrm{gm}^{-3}$ with average concentration of $419 \mu \mathrm{g} \mathrm{m}^{-3}$. Meanwhile, 6 hours $\mathrm{PM}_{2.5}$ concentrations were ranged from 103 to 621 $\mu \mathrm{gm}^{-3}$ with mean concentration of $254 \mu \mathrm{g} \mathrm{m}^{-3}$. In comparison with Karachi, the average mean concentration of PM was observed to be $239 \mu \mathrm{g} \mathrm{m}^{-}$ ${ }^{3}$ in 1985 and increased to 265,275 , and $328 \mu \mathrm{g} \mathrm{m}^{-3}$ in 1986, 1987 and 1988, respectively, and the annual average PM concentration during 1987 and 1988 in Karachi at the Sindh Industrial Trading Estate and Sadar sites were recorded 254, 459 and 333, $397 \mu \mathrm{g} \mathrm{m} \mathrm{m}^{-3}$ respectively [1]. Majority size segregated pollutants in current study (TSP, PM 10 , $\mathrm{PM}_{2.5}$ ) were higher than the US-EPA, WHO and NEQS-Pak [17-19], only 4\%, $8 \%$ and $4 \%$ for TSP, $\mathrm{PM}_{10}$ and $\mathrm{PM}_{2.5}$ samples were found under prescribed guidelines. The highest average concentration of segregated pollutants (TSP, $\mathrm{PM}_{10}$, and $\mathrm{PM}_{2.5}$ ) were observed at Satiana road followed by Gutewala and Railway Station.

We have also estimated cumulative percentage (\%) distribution of all segregated pollutants to each site having more $50 \%$ contribution to total size segregated pollutants. The highest average concentrations of segregated pollutants (TSP, $\mathrm{PM}_{10}$, and $\mathrm{PM}_{2.5}$ ) were observed at Satiana road followed by Gutewala and Railway Station. These three sites are industrial areas and situated in industrial clusters and further size 
segregated pollutants concentrations were increased due to the major road intersections that are heavily dense by traffic load and busy business commercial centers round the clock. Similarly, increased level of size segregated pollutants at Madina Food Mills and Tariqabad were likely due to emissions from brick kilns and industrial emissions situated upwind and proximal to these monitoring points. Moreover, higher level of size segregated pollutants at these sampling sites were mainly due to re-suspended road dust and emissions from public and commercial transportation (i.e. two wheelers trucks, autorickshaws vans, and buses) which are in line with the findings of [20-22]. Overall, sampling locations exhibited poor air quality due to high traffic density which mainly consists of heavy duty vehicles such as trucks, local buses, trailers, vans, and tractors moving along the roads. Most of the vehicles are usually old, poorly maintained, overloaded, and smoky and use inefficient engines that consume bad quality fuel which were increased PM concentrations [1, 21-22]. The air born pollutants originated from exhaust and nonexhaust sources in the urban environments. Plying vehicles are a main source of such type of particle emissions and these could share up to $90 \%$ in polluted urban environments [23-24]. The measured size segregated PMs in urban areas were found higher during some periods of the year and this situation may became more worse in coming year due to the increased population and heavy traffic load in big cities like Faisalabad. While, at typical urban sites (Al-Noor Colony and Kekshian Colony), the size segregated concentrations were significantly low because these areas have relatively low vehicular and industrial activities in the surroundings.

Table 1. Descriptive statistical analysis of urban and peri-urban areas in metropolitan Faisalabad.

\begin{tabular}{|c|c|c|c|c|c|c|}
\hline & \multicolumn{3}{|c|}{$\begin{array}{c}\text { Size segregated PM } \\
\text { urban areas* }\end{array}$} & \multicolumn{3}{|c|}{$\begin{array}{l}\text { Size segregated PM } \\
\text { Peri-urban areas** }\end{array}$} \\
\hline & TSP & $P M_{10}$ & $P M_{2.5}$ & TSP & $P M_{10}$ & $P M_{2.5}$ \\
\hline Minimum & 154 & 110 & 21 & 77 & 40 & 9 \\
\hline Maximum & 987 & 782 & 621 & 1123 & 893 & 654 \\
\hline Mean $\left({ }^{+} n=25\right)$ & 662 & 419 & 246 & 323 & 191 & 120 \\
\hline $\mathrm{SD}^{\mathrm{a}}$ & 243 & 207 & 134 & 250 & 188 & 130 \\
\hline
\end{tabular}

\section{Size segregated pollutants concentration in peri- urban areas}

Maximum 6 hours TSP concentrations were recorded at Chak $215 \mathrm{RB}\left(1123 \mu \mathrm{g} \mathrm{m} \mathrm{m}^{-3}\right)$ followed by Chak $238\left(785 \mu \mathrm{g} \mathrm{m}^{-3}\right)$, Chak 237 (614 $\mu \mathrm{g} \mathrm{m}^{-3}$ ) (Table 1). Minimum 6 hours TSP concentration was monitored at Chak $226 \mathrm{RB}$ (77 $\left.\mu \mathrm{g} \mathrm{m} \mathrm{m}^{-3}\right)$. Similarly, maximum 6 hours $\mathrm{PM}_{10}$ concentrations were recorded at Chak 215 (893 $\mu \mathrm{g}$ $\left.\mathrm{m}^{-3}\right)$ followed by Chak $238\left(542 \mu \mathrm{g} \mathrm{m}^{-3}\right)$, and Chak $237\left(419 \mu \mathrm{g} \mathrm{m}^{-3}\right.$ ). Minimum 6 hours $\mathrm{PM}_{10}$ concentration was observed at Chak $255 \mathrm{RB}$ (40 $\mu \mathrm{g} \mathrm{m}^{-3}$ ), while the maximum 6 hours $\mathrm{PM}_{2.5}$ concentrations were observed at Chak 215RB (654 $\left.\mu \mathrm{g} \mathrm{m}^{-3}\right)$, Chak $238\left(254 \mu \mathrm{g} \mathrm{m}^{-3}\right)$ and Chak 237 (267 $\left.\mu \mathrm{g} \mathrm{m}^{-3}\right)$. Meanwhile the minimum concentration was recorded at Chak $244\left(9 \mu \mathrm{g} \mathrm{m}^{-3}\right)$.

The variations of all size segregated pollutants in peri-urban areas were also highly significant and different from each other at all monitoring points. The 6 hours TSP concentration in peri-urban areas were ranged from 77 to 1123 ${\mu \mathrm{gm}^{-3}}^{-3}$ with average mean $654 \mu \mathrm{g} \mathrm{m}^{-3}$. The highest concentration of size segregated pollutants (TSP, $\mathrm{PM}_{10}$, and $\mathrm{PM}_{2.5}$ ) were observed at Chak 215, Chak 238 and Chak 237. We have also estimated cumulative percentage (\%) distribution of all segregated pollutants to each site having more $50 \%$ contribution to total size segregated pollutants. Box and whisker plot suggested (TSP, $\mathrm{PM}_{10}$, and $\mathrm{PM}_{2.5}$ ) distribution in peri-urban areas (Fig. 1). Increased concentration was attributed to clusters of brick kilns which were found near the monitoring sites (Chak 215 and Chak 238). Moreover, poor and unpaved roads were found at Chak 238.

In our finding, 6 hours $\mathrm{PM}_{10}$ concentrations were varied from 40 to $893 \mu \mathrm{g} \mathrm{m}^{-3}$ with an average concentration of $191 \mu \mathrm{g} \mathrm{m}$. Urban cities depicted different pattern for $\mathrm{PM}_{10}$ concentrations decreasing from Lahore (368 $\mu \mathrm{g}$ $\left.\mathrm{m}^{-3}\right)$, Peshawar $\left(350 \mu \mathrm{g} \mathrm{m}^{-3}\right)$, Quetta $\left(331 \mu \mathrm{g} \mathrm{m}^{-3}\right)$, Karachi $\left(302 \mu \mathrm{g} \mathrm{m}^{-3}\right)$, Islamabad $\left(280 \mu \mathrm{g} \mathrm{m}^{-3}\right)$, to Rawalpindi (276 $\mathrm{g} \mathrm{m}^{-3}$ ) [9]. Meanwhile, current 6 hours $\mathrm{PM}_{2.5}$ concentrations were assorted from 9 to $654 \mu \mathrm{g} \mathrm{m}^{-3}$ with mean concentration $120 \mu \mathrm{g} \mathrm{m}^{-3}$. Majority of size segregated PMs (TSP, $\mathrm{PM}_{10}$, $\mathrm{PM}_{2.5}$ ) were found higher than US-EPA, WHO and 
NEQS-Pak guidelines. On the other hand, size segregated pollutants include TSP (40\%) $\mathrm{PM}_{10}$ $(60 \%)$ and $\mathrm{PM}_{2.5}(44 \%)$ samples in peri-urban were observed under the permissible limits of US-EPA, WHO, and NEQS-Pak. In order to analyze $\mathrm{PM}_{2.5}$ and $\mathrm{PM}_{10}$ concentrations in Islamabad during 2002-2005, Hopke et al. [25] found that the average concentrations were 15 and $68 \mu \mathrm{g} \mathrm{m}^{-3}$, respectively, which is close to the present study. However, low levels of size segregated pollutants in peri-urban areas were attributed to the low emissions and paved roads around the sampling sites.
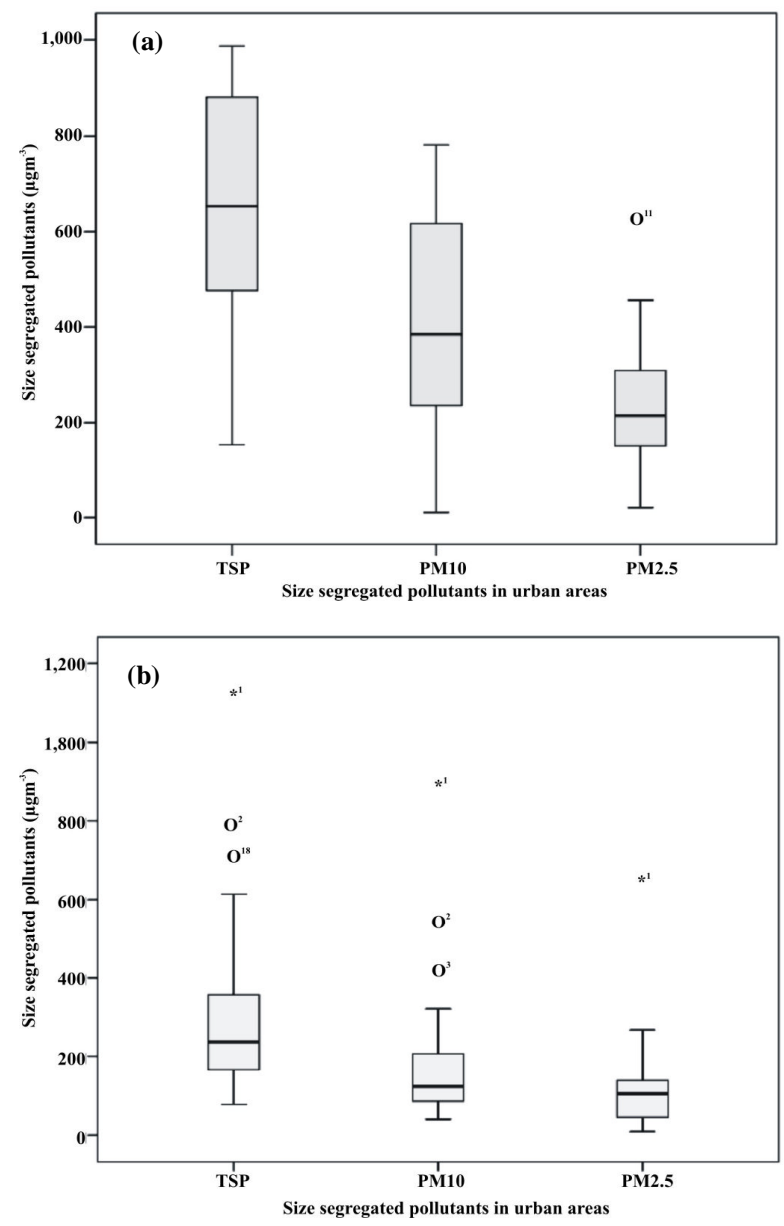

Figure 1. Box and whisker plot of size segregated PMs distribution in (a) urban and (b) peri-urban areas of metropolitan Faisalabad

\section{Comparison with other Asian countries}

As indicated in (Fig. 2), comparisons of average 6 hours size segregated pollutant $\left(\mathrm{PM}_{10}\right)$ level in current study with other metropolitan's cities of Pakistan and Asian cities illustrate that the mass concentration was highest in Faisalabad metropolitan than all others cities of the world. In 2008, Gurjar et al. [26] suggested that the Karachi was the highest polluted cities in world regarding TSP concentration. However, World Bank highlighted that $\mathrm{PM}_{10}$ concentration was decreased

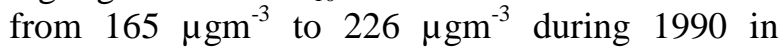
Pakistan. Keeping in view the sporadic investigations, an increasing pattern of size segregated pollutants level will prevail in Faisalabad metropolitan Pakistan and other Asian metropolitans in future.

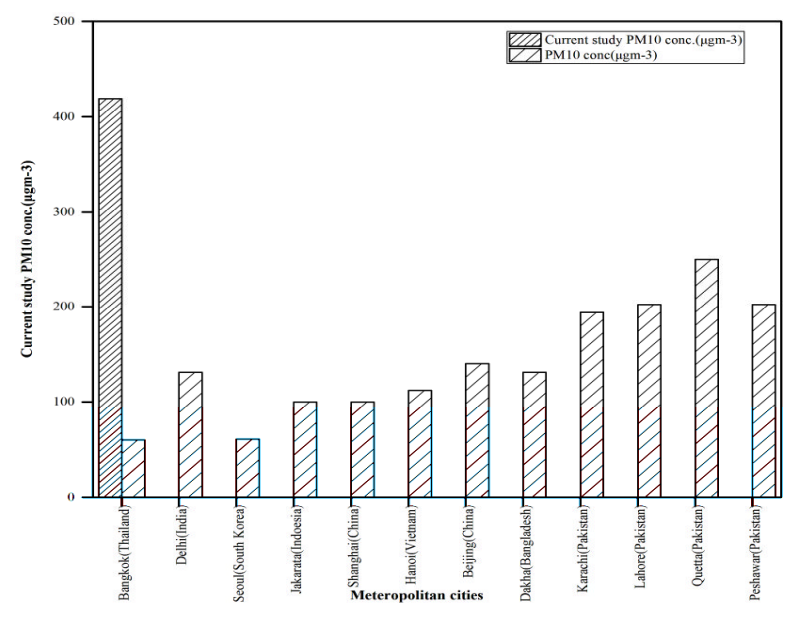

Figure 2. Comparison of size segregated pollutant $\left(\mathbf{P M}_{10}\right)$ with Pakistan metropolitans and other Asian cities with current study $[31-37,7]$

\section{Control strategy in urban and peri-urban areas}

Better air quality becomes more effective if it includes the assessment of how to rationalize the necessary outlays. Several studies have reported to investigate air pollution in Faisalabad areas [27-30]. None of them have suggested about improving the air quality of Faisalabad. In our point of view, the strategy to reduce size segregated pollutant reduction is depicted in (Fig. 3). In order to improve air quality in iFaisalabad, limiting both industrials and vehicular emissions in urban areas will be obligatory. From the obtained results in urban areas we suggest that at an industrial level environmental engineering techniques should be introduce such as thrust for cleaner techniques (flu gas desulfurization, combustion adjustment for NOx mitigation gravity (gravitational chamber), centrifugation (cyclone 
separator), filtration (fabric filter system), scrubbing (dry \& wet scrubber), electrostatic precipitators (electrostatic force to separate dust particles from exhaust gases), combustion systems (thermal oxidizers), condensers, absorbers, absorbers). Incentives should be given for those industries who adopt air quality control measures. For the effectiveness of these measures, database about air cleaner performance should be maintained and updated regularly. Faisalabad has developed exponentially through a logistic and economic nightmare. High loads of vehicles on roads require extension transport infrastructure, and mass rapid transport system should be in place to reduce the vehicular emissions loads especially at intersection or chowks in Faisalabad [31]. In addition, strict monitoring and compliance of NEQS-Pak quality standard are needed to improve air quality.

Highest size segregated pollutant concentrations in peri-urban areas were observed and call for immediate attention for government and researchers. Keeping in view the upward increasing trend in peri-urban areas demand for paved roads should be constructed to avoided coarse particles originated from roads dust. Additionally, brick kilns should be situated far away from peri-urban areas to limit the exposure of human from pollutants emissions.

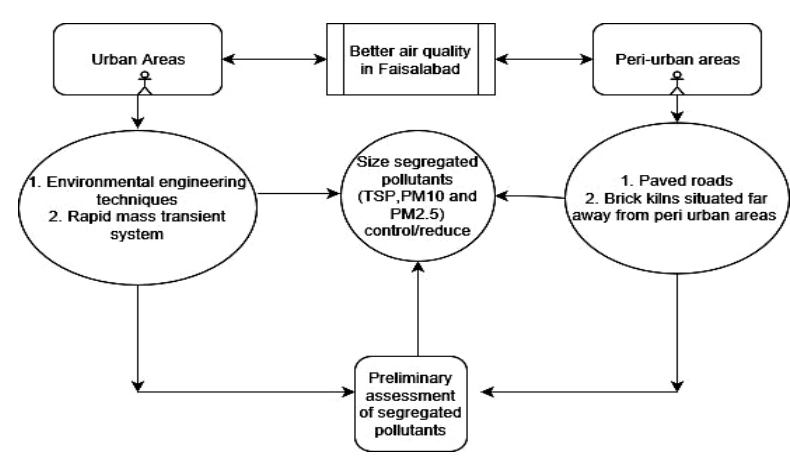

Figure 3. Schematic diagram about strategy to improve air quality in urban and peri-urban areas of metropolitan Faisalabad

\section{Conclusion}

The current study indicated a significant variation of mass concentrations of different size segregated pollutants in urban and peri-urban areas of the Faisalabad metropolitan. Size segregated pollutant concentrations were higher in urban area attributed to industrial emissions and high traffic loads, while in peri-urban brick kilns emissions, unpaved roads were contributing to higher level of size segregated pollutant. Majority of size segregated pollutant (TSP, $\mathrm{PM}_{10}, \mathrm{PM}_{2.5}$ ) were higher than the US-EPA, WHO and NEQS-Pak limits for both urban and peri-urban areas. We concluded that both urban and peri-urban areas were highly polluted and posing potential threats to inhabitants. It is suggested that size segregated pollutant could be controlled by using environmental engineering techniques. Furthermore, complete restrict emissions related to transporttations are required to control size segregated polluted. In peri-urban areas, paved roads should be constructed and brick kilns should be situated far away from outskirts areas to avoid minimal exposure. Urgent mitigation measures and strategy should be adopted to control the size segregated pollutant for better air quality in metropolitan Faisalabad and thus improving the air quality for ecosystems sustainability and mars the serenity of the real estate environment at large for habitation.

\section{Acknowledgement}

This study was economically supported by Higher Education Commission, Islamabad, Pakistan.

\section{References}

1. M. H. Shah and N. Shaheen, Atmos. Res., 95 (2010) 223.

https://doi.org/10.1016/j.atmosres.2009.10.001

2. Wu, Y., Wang, P., Yu, S. et al. Environ. Chem. Lett., 16 (2018) 1117. https://doi.org/10.1007/s10311-018-0735-6

3. K. Mehmood et al, Environ. Chem. Lett., 16 (2018) 301. doi: 10.1007/s10311-017-0675-6.

4. M. Jamaludddin Ahmed and Md. Khorshed Ali, Int. J. Res. Chem. Environ., 2 (2012) 220 http://www.ijrce.org/abstract.php?article id=840

5. L Wang, P. Li, S. Chang, S. Yu, K. Mehmood et al, Sci. Rep., 8 (2018) 934. doi:10.1038/s41598-018-19481-0.

6. UNEP, Geo-2000, UNEP, (1999) http://www.grid.unep.ch/geo2000/english/00 70.htm. 
7. WHO, Ambient air quality and health., Fact sheet N 313. WHO media Centre. (2014) available http://www.who.int/mediacentre/factsheets/fs 313/e n/.

8. Chakraborty et al., Environ. Sci. Technol., 44 (2010) 21, 8038. doi:10.1021/es $102029 \mathrm{t}$

9. Pak-EPA/JICA, (2001) Available at http://www.environment.gov.pk/pub-pdf/ city-inv.pdf. accessed on 3 July 3, 2008

10. J. S. Racki, World Bank environment. John Wiley and Sons, (2006) Report.

11. World Bank, Vol. II Technical Annex (2006) World Bank Report NO.36946-PK.October, Asia1818h Street, Washington DC, 20433, USA.

12. K. Anwar, S. Ejaz, M. Ashraf, N. Ahmad, \& A. Javeed, Environ Sci. Pollut. Res. Int., 20 (2013) 4586. doi:10.1007/s11356-012-1383-1

13. W. Javed, A. S. Wexler, G. Murtaza, H. R. Ahmad, \&S. M. A. Basra, Atmosfera, 28 (2015) 2: 99. https://doi.org/10.1016/S0187-6236(15)30003-5

14. L. Yu, G. Wang, R. Zhang, L. Zhang, Y. Song, B. Wu, X. Li. K. and J. Chu, Aero. Air. Qual. Res., 13 (2013) 583. DOI: $10.4209 /$ aaqr.2012.07.0192

15. M. A. Alolayan, K. W. Brown, J. S. Evans, W. S. Bouhamra and P. Koutrakis, Sci. Total. Environ., 448 (2013) 14. https://doi.org/10.1016/j.scitotenv.2012.11.090

16. K. N. Cheung, W. Daher, M. M. Kam, M. M. Shafer, Z. Ning, J. J. Schauer and C. Sioutas, Atmos. Environ., 45 (2011) 2662. https://doi.org/10.1016/j.atmosenv.2011.02.066

17. U. S. EPA, Office of Air Quality Planning and Standards, (2012) EPA 454/R99-010. https://nepis.epa.gov/Exe/ZyPDF.cgi?Docke $\mathrm{y}=2000$ TSUX.PDF

18. WHO, WHO Regional Office for Europe Scherfigsvej 8 DK-2100 Copenhagen, Denmark, (2005) 92890-2192 6.

http://www.euro.who.int/en/home/sections/ne ws/2013/03/whoeurope-in-copenhagenmoving-to-new-premises

19. Pak EPA, (2012), Government of Pakistan.

20. S. Z. Ilyas, Worl. Appl. Sci. J., 1 (2006) 126 doi : 10.5829/idosi.wasj

21. M. Sami, W. Amir, A. Sher A, J. Zhej. Uni. Sci. Bio., 7 (2006) 547. doi: 10.1631/jzus.2006.B0542

22. I. Colbeck, Z. A. Nasir, S. Ahmad, et al, Aero. Air Qual. Res., 11 (2011) 689. https://doi.org/10.4209/aaqr.2010.10.0087

23. N. Ashraf, M. Muhammad, S. Bushra, I. Munawar, I. Ullah and A. S. Shaukat A. S. Int. J. Chem. Biochem. Sci., 3 (2013) 28. doi=10.1.1.718.2137

24. P. K. Hopke, D. D. Cohen, B. A. Begum et al, Sci. Tota. Environ., 404 (2008) 112. https://doi.org/10.1016/j.scitotenv.2008.05.039

25 B. R. Gurjar, T. M. Butler,M. J. Lawrence, J. Lelieveld, Atmos. J., 42 (2008) 1606. doi:10.1016/j.atmosenv.2010.08.011

26. M. Shahid, A. K. and K. Hussain, Int. J. Chem. Mat. Sci., 2 (2014) 1.

27. J. Waseem, G. Murtaza, H. R. Ahmad, Poll. Res., 34 (2015b) 7.

28. Y. Niaz, J. T. Zhou and Z. Yu, Int. J. Agric. Biol. Eng., 1 (2015) 116. doi: 10.3965/j.ijabe.20150801.015

29. K. Mehmood, University of agriculture Faisalabad, (2013) M.Sc. (Hons.) Thesis

30. J. G. Calvert, J. B. Haywood, R. F. Sawyer and J. H. Seinfeld, Sci., 261 (1993) 37. https://doi.org/10.1126/science.261.5117.37

31. PCD, In: Schwela D, Haq G, Huizenga C et al. Earth Scan 8-10 Camden high street, London, (2006) 177.

32. CPCD, (2006) http://www.cpcb.nic.in/Annual\%20Report/Previo us\%20Year/AnnualReport_2005-2006.pdf

33. MOE D. Schwela, G. Haq, C. Huizenga $C$ et al, Camden high street, London, 75 (2006) 47. MOE Ministry of Environment Indonesia.

34. BJEPB D. Schwela, G. Haq and C. Huizenga et al. Earth scan 8-10 Camden high street, London, (2006) 177.

35. M. Khaliquzzaman, (2005). http://siteresources.worldbank.org/INTVIET NAM/Resources/MKZAirQualityIssuesHano i4.pdf

36. J. Fu, cited in D. Schwela D, G. Haq and C. Huizenga et al., Urban air pollution in Asian cities, Earth scan 8-10 Camden High Street, London, (2006) 190.

37. SDNP, Aero. Air Qual. Res., 13 (2007) 583.

38. I. J. Chaudhary and D. Rathore. Atmosp. Pollut. Res. 9: (2018) 1072. $\underline{\text { https://doi.org/10.1016/j.apr.2018.04.006 }}$ 